\title{
Author Correction: Search and rescue at sea aided by hidden flow structures
}

Mattia Serra (D), Pratik Sathe (D), Irina Rypina (D), Anthony Kirincich (D), Shane D. Ross (D), Pierre Lermusiaux, Arthur Allen, Thomas Peacock (1) \& George Haller (i)

Correction to: Nature Communications https://doi.org/10.1038/s41467-020-16281-x, published online 26 May 2020.

The original version of this Article contained an incorrect hyperlink in reference 17. This has now been corrected in the PDF and HTML versions of the Article.

Published online: 25 June 2020

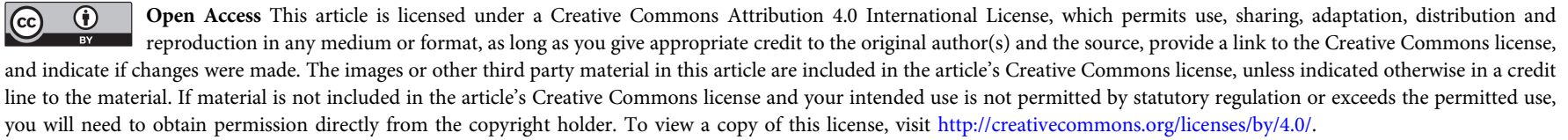

(C) The Author(s) 2020 